\title{
Inferior vena cava thrombus with pulmonary embolism complicating amebic liver abscess
}

\author{
Vinaykumar Thati • Sanjay Nagral
}

Published online: 17 August 2013

(C) Indian Society of Gastroenterology 2013

Amebic liver abscess leading to hepatic vein thrombus is described, but pulmonary embolism is exceedingly rare $[1,2]$. This 50 -year-old male presented with fever, upper abdominal pain since 10 days, chest pain, and breathlessness since 2 days. There were tachycardia, tachypnea, and tenderness in the right upper abdomen. Leukocyte count was $27,000 / \mathrm{mm}^{3}$, and liver function tests were normal. Indirect hemagglutination test for amebiasis was positive. On ultrasound, there was a $7.7 \mathrm{~cm} \times 5.4 \mathrm{~cm}$ abscess in segment 8 of the liver and a thrombus in the right hepatic vein extending

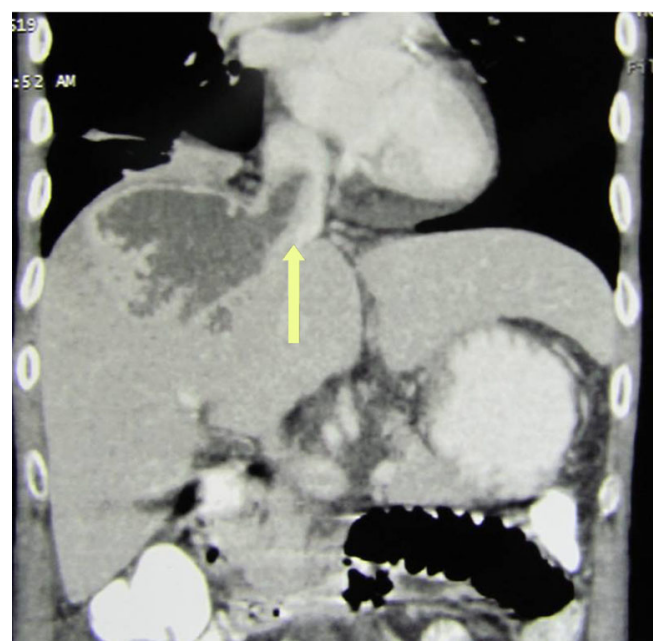

Fig. 1 CT abdomen showing a liver abscess thrombus in the right hepatic vein and inferior vena cava (arrow)

V. Thati $(\bowtie) \cdot$ S. Nagral

Department of General Surgery, K B Bhabha Hospital, R K Patkar Marg, Bandra (West), Mumbai 400 050, India

e-mail: drvinaykthati@yahoo.com into the inferior vena cava. Computed tomography (CT) scan of the abdomen showed a liver abscess with thrombus in the right hepatic vein and inferior vena cava (Fig. 1) and thrombus in the first segmental branch of the right pulmonary artery (Fig. 2) with no infarction. Treatment was with percutaneous aspiration, metronidazole, and low molecular weight heparin with which symptoms resolved in 2 weeks with a resolution of the pulmonary thrombus on follow up CT.

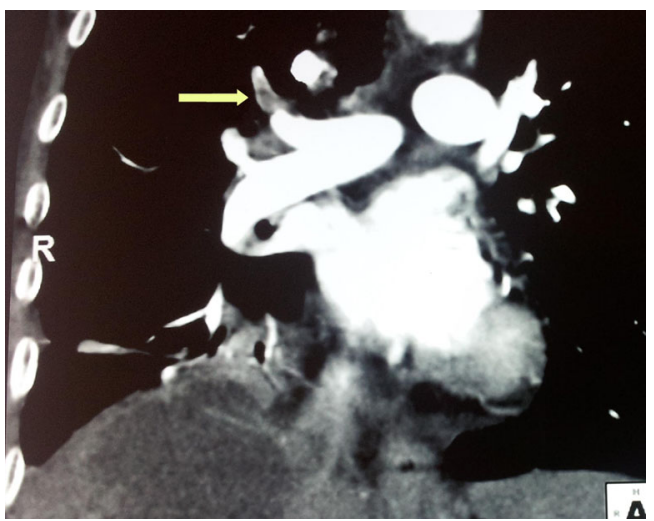

Fig. 2 CT showing a thrombus in the first segmental branch of the right pulmonary artery

\section{References}

1. Sarda AK, Mittal R, Basra BK, Mishra A, Talwar N. Three cases of amoebic liver abscess causing inferior vena cava obstruction, with a review of the literature. Korean J Hepatol. 2011;17:71-5.

2. Hodkinson J, Couper-Smith J, Kew MC. Inferior vena caval and right atrial thrombosis complicating an amebic hepatic abscess. Am J Gastroenterol. 1988;83:786-8. 